\title{
One-year outcomes of coronary artery bypass graft surgery versus percutaneous coronary intervention with multiple stenting for multisystem disease: A meta-analysis of individual patient data from randomized clinical trials
}

\author{
Nestor Mercado, MD, PhD, ${ }^{\text {a,f }}$ William Wijns, MD, PhD, ${ }^{b}$ Patrick W. Serruys, MD, PhD, ${ }^{a}$ Ulrich Sigwart, MD, ${ }^{\mathrm{c}}$ \\ Marcus D. Flather, MBBS, ${ }^{d}$ Rodney H. Stables, DM, FRCP, ${ }^{e}$ William W. O'Neill, MD, ${ }^{f}$ Alfredo Rodriguez, MD, ${ }^{g}$

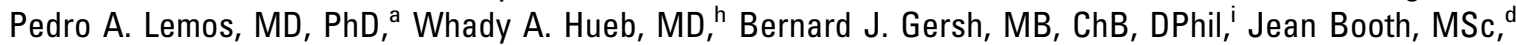 \\ and Eric Boersma, $\mathrm{PhD}^{\mathrm{a}}$
}

\begin{abstract}
From the Department of Interventional Cardiology and Clinical Epidemiology Unit, Thoraxcenter, ${ }^{a}$ Erasmus MC, Rotterdam, incidence of repeat revascularization at 1 year. All analyses were based on the intention-to-treat principle.
\end{abstract} The Netherlands; Cardiovascular Center, OLV Hospital, ${ }^{\mathrm{b}}$ Aalst, Belgium; Division of Cardiology, University Hospital, ${ }^{c}$ Geneva, Switzerland; Clinical Trials and Evaluation Unit, Royal Brompton and Harefield NHS Trust, ${ }^{\mathrm{d}}$ London, United Kingdom; Cardiothoracic Centre, ${ }^{e}$ Liverpool, United Kingdom; Department of Medicine and Division of Cardiology William Beaumont Hospital, ${ }^{\mathrm{f}}$ Royal Oak, Mich; Otamendi Hospital, ${ }^{\mathrm{g}}$ Buenos Aires, Argentina; Heart Institute of the University of São Paulo, ${ }^{\mathrm{h}}$ São Paulo, Brazil; and Division of Cardiovascular Diseases, Mayo Clinic and Mayo Foundation, ${ }^{\mathrm{i}}$ Rochester, Minn.

Received for publication March 26, 2004; revisions received Dec 21, 2004; accepted for publication Dec 23, 2004.

Address for reprints: Eric Boersma, PhD, Clinical Epidemiology Unit, Room H-543, Department of Cardiology, Thoraxcenter, Erasmus Medical Center, Dr Molewaterplein 40, 3015 GD Rotterdam, The Netherlands (E-mail: h.boersma@erasmusmc.nl).

J Thorac Cardiovasc Surg 2005;130:512-9

$0022-5223 / \$ 30.00$

Copyright (C) 2005 by The American Association for Thoracic Surgery

doi:10.1016/j.jtcvs.2004.12.049

Results: After 1 year of follow-up, $8.7 \%$ of patients randomized to percutaneous coronary intervention with multiple stenting versus $9.1 \%$ of patients randomized to coronary artery bypass graft surgery reached the primary clinical end point (hazard ratio 0.95 and $95 \%$ confidence interval $0.74-1.2$ ). Repeat revascularization procedures occurred more frequently in patients allocated to percutaneous coronary intervention with multiple stenting compared with coronary artery bypass graft surgery (18\% vs $4.4 \%$; hazard ratio 4.4 and $95 \%$ confidence interval $3.3-5.9)$. The percentage of patients who were free from angina was slightly lower after percutaneous coronary intervention with multiple stenting than after coronary artery bypass graft surgery $(77 \%$ vs $82 \% ; P=.002)$.

Conclusions: One year after the initial procedure, percutaneous coronary intervention with multiple stenting and coronary artery bypass graft surgery provided a similar degree of protection against death, myocardial infarction, or stroke for patients with multisystem disease. Repeat revascularization procedures remain high after percutaneous coronary intervention, but the difference with coronary artery bypass graft surgery has narrowed in the era of stenting.

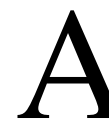
$t$ the end of the past century, cardiovascular disease (CVD) accounted for approximately $50 \%$ of deaths in the developed world and $25 \%$ of deaths in the developing world. Among CVD deaths, approximately $43 \%$ are the
Background: We aimed to provide a quantitative analysis of the 1-year clinical outcomes of patients with multisystem coronary artery disease who were included in recent randomized trials of percutaneous coronary intervention with multiple stenting versus coronary artery bypass graft surgery.

Methods: An individual patient database was composed of 4 trials (Arterial Revascularization Therapies Study, Stent or Surgery Trial, Argentine Randomized Trial of Percutaneous Transluminal Coronary Angioplasty Versus Coronary Artery Bypass Surgery in Multivessel Disease 2, and Medicine, Angioplasty, or Surgery Study 2) that compared percutaneous coronary intervention with multiple stenting $(\mathrm{N}=1518)$ versus coronary artery bypass graft surgery $(\mathrm{N}=1533)$. The primary clinical end point of this study was the combined incidence of death, myocardial infarction, and stroke at 1 year after randomization. Secondary combined end points included the result of coronary artery disease (CAD), and by 2020 CAD will become the world's 
TABLE 1. Design characteristics of the trials included in this meta-analysis

\begin{tabular}{|c|c|c|c|c|}
\hline & ARTS & SoS & ERACI-2 & MASS-2 \\
\hline Enrollment period & 1997-1998 & 1996-1999 & 1996-1998 & $1995-2000$ \\
\hline $\begin{array}{l}\text { Number of screened } \\
\text { patients }\end{array}$ & NA & NA & 2,759 & 18,692 \\
\hline $\begin{array}{l}\text { Number of eligible } \\
\text { patients }\end{array}$ & NA & NA & 1,076 & 2,076 \\
\hline $\begin{array}{l}\text { Number of randomized } \\
\text { patients }\end{array}$ & 1205 & 988 & 450 & $408^{*}$ \\
\hline \multirow[t]{3}{*}{$\begin{array}{l}\text { Major inclusion } \\
\text { criteria }\end{array}$} & $\begin{array}{l}\text { Stable or unstable angina, } \\
\text { or silent ischemia }\end{array}$ & $\begin{array}{l}\text { Stable or unstable } \\
\text { angina }\end{array}$ & $\begin{array}{l}\text { Stable or unstable } \\
\text { angina, or } \\
\text { asymptomatic } \\
\text { patients with } \\
\text { myocardium at risk } \\
\text { (>2 areas with } \\
\text { perfusion defects) }\end{array}$ & $\begin{array}{l}\text { Stable angina or } \\
\text { asymptomatic } \\
\text { patients with } \\
\text { objective evidence of } \\
\text { myocardial ischemia }\end{array}$ \\
\hline & $\begin{array}{l}\text { Angiographically proven } \\
\text { multivessel disease with } \\
1 \text { or more significant } \\
\text { stenoses in at least } 2 \\
\text { major epicardial } \\
\text { coronary arteries }\end{array}$ & $\begin{array}{l}\text { Angiographically proven } \\
\text { multivessel disease } \\
\text { with } 1 \text { or more } \\
\text { significant stenoses } \\
\text { in at least } 2 \text { major } \\
\text { epicardial coronary } \\
\text { arteries }\end{array}$ & $\begin{array}{l}\text { Angiographically proven } \\
\text { multivessel disease } \\
\text { with } 1 \text { or more } \\
\text { significant stenoses } \\
\text { in at least } 2 \text { major } \\
\text { epicardial coronary } \\
\text { arteries }\end{array}$ & $\begin{array}{l}\text { Angiographically proven } \\
\text { multivessel disease } \\
\text { with } 1 \text { or more } \\
\text { significant stenoses } \\
\text { in at least } 2 \text { major } \\
\text { epicardial coronary } \\
\text { arteries }\end{array}$ \\
\hline & $\begin{array}{l}\text { Equivalent degree of } \\
\text { revascularization was } \\
\text { mandatory }\end{array}$ & $\begin{array}{l}\text { Equivalent degree of } \\
\text { revascularization was } \\
\text { not mandatory }\end{array}$ & $\begin{array}{l}\text { Complete functional } \\
\text { revascularization }\end{array}$ & $\begin{array}{l}\text { Equivalent degree of } \\
\text { revascularization was } \\
\text { mandatory }\end{array}$ \\
\hline \multirow[t]{4}{*}{$\begin{array}{l}\text { Major exclusion } \\
\text { criteria }\end{array}$} & Previous $\mathrm{CABG}$ or $\mathrm{PCl}$ & Previous $\mathrm{CABG}$ or $\mathrm{PCl}$ & $\begin{array}{l}\text { Previous CABG or } \mathrm{PCI} \\
\text { (in the last year) }\end{array}$ & Previous CABG or $\mathrm{PCl}$ \\
\hline & $\begin{array}{l}\text { Need for concomitant } \\
\text { major cardiovascular } \\
\text { surgery }{ }^{-}\end{array}$ & $\begin{array}{l}\text { Need for concomitant } \\
\text { major cardiovascular } \\
\text { surgery } \dagger\end{array}$ & $\begin{array}{l}\text { Concomitant severe } \\
\text { valvular heart disease }\end{array}$ & $\begin{array}{l}\text { Concomitant valvular } \\
\text { heart disease }\end{array}$ \\
\hline & Left main stenosis & & & Left main stenosis \\
\hline & $\begin{array}{l}\text { Transmural MI within the } \\
\text { previous week }\end{array}$ & $\begin{array}{l}\mathrm{Ml} \text { in the } 48 \mathrm{~h} \text { before } \\
\text { the revascularization } \\
\text { procedure }\end{array}$ & $\begin{array}{l}\mathrm{MI} \text { in the } 48 \mathrm{~h} \text { before } \\
\text { the revascularization } \\
\text { procedure }\end{array}$ & $\begin{array}{l}\text { MI or unstable angina } \\
\text { requiring emergency } \\
\text { revascularization }\end{array}$ \\
\hline Primary end point & $\begin{array}{l}\text { 12-month MACCE-free } \\
\text { survival }\end{array}$ & $\begin{array}{l}\text { Rate of repeat } \\
\text { revascularization }\end{array}$ & $\begin{array}{l}\text { MACE rate within } 30 \mathrm{~d} \\
\text { and need for } \\
\text { emergency or } \\
\text { elective repeat } \\
\text { revascularization } \\
\text { procedures at } 30 \mathrm{~d}\end{array}$ & $\begin{array}{l}\text { Composite end point of } \\
\text { cardiac death, } \\
\text { nonfatal myocardial } \\
\text { infarction, and } \\
\text { refractory angina } \\
\text { requiring } \\
\text { revascularization }\end{array}$ \\
\hline
\end{tabular}

ARTS, Arterial Revascularization Therapies Study; SoS, Stent or Surgery Trial; ERACI-2, Argentine Randomized Trial of Percutaneous Transluminal Coronary Angioplasty Versus Coronary Artery Bypass Surgery in Multivessel Disease 2; MASS-2, Medicine, Angioplasty, or Surgery Study 2; NA, not available; MI, myocardial infarction; $C A B G$, coronary artery bypass graft; $P C l$, percutaneous coronary intervention; $M A C E$, major adverse cardiac events defined as death, Q-wave $\mathrm{MI}$, or stroke; $M A C C E$, major adverse cardiac or cerebrovascular events, defined as death; stroke, transient ischemic attacks, and reversible ischemic neurologic deficits; documented nonfatal myocardial infarction; and repeated revascularization by percutaneous coronary intervention or surgery. *Patients randomized to PCI or CABG surgery; the medical treatment arm of MASS-2 was excluded. $\dagger$ Defined as valve surgery, resection of aortic or left ventricular aneurysm, carotid endarterectomy, or abdominal aortic aneurysm surgery.

most prevalent cause of death and disability. ${ }^{1}$ Approximately $60 \%$ of patients with CAD have symptomatic multivessel disease that could be treated by either percutaneous coronary intervention (PCI) or coronary artery bypass graft $(\mathrm{CABG})$ surgery. $^{2}$ Therefore, given the magnitude of the problem, a better understanding of the invasive manage- ment and clinical outcome of patients with CAD is of critical public health importance.

The last 2 decades witnessed major advances in coronary revascularization techniques for $\mathrm{CAD}$, and several randomized clinical trials compared PCI against CABG surgery for the treatment of chronic, multisystem $\mathrm{CAD} .^{3}$ In addition, 3 
TABLE 2. Baseline profile, medications, and periprocedural characteristics of the patients included in the intention-totreat analysis

\begin{tabular}{|c|c|c|}
\hline & $\begin{array}{l}\text { PCl with stenting } \\
\text { (N }=1518)\end{array}$ & $\begin{array}{c}\text { CABG } \\
(N=1533)\end{array}$ \\
\hline Men & 77 & 77 \\
\hline Age (y) & $61(53-68)$ & $61(54-68)$ \\
\hline Diabetes mellitus & 18 & 18 \\
\hline Hypertension & 50 & 51 \\
\hline Hypercholesterolemia & 53 & 53 \\
\hline Family history of CAD & 40 & 39 \\
\hline Current smoker & 20 & 26 \\
\hline Previous MI & 43 & 41 \\
\hline Peripheral vascular disease & 7 & 8 \\
\hline Aspirin & 94 & 90 \\
\hline$\beta$-blockers & 73 & 75 \\
\hline Calcium channel blockers & 37 & 40 \\
\hline Nitrates & 68 & 70 \\
\hline Statins & 49 & 47 \\
\hline \multicolumn{3}{|l|}{ Enrollment diagnosis* } \\
\hline Stable angina & 66 & 69 \\
\hline Unstable angina & 29 & 27 \\
\hline Silent ischemia & 5 & 4 \\
\hline Ejection fraction $(\%)$ & $60(52-88)$ & $60(52-88)$ \\
\hline $\begin{array}{l}\text { No. of segments with stenosis } \\
>50 \% \text { of luminal diameter }\end{array}$ & $3(2-3)$ & $3(2-3)$ \\
\hline \multicolumn{3}{|l|}{ Number of diseased vessels } \\
\hline 2 & 59 & 54 \\
\hline 3 & 41 & 46 \\
\hline \multicolumn{3}{|l|}{ Vessel territory with stenosis } \\
\hline Right coronary artery & 74 & 76 \\
\hline Left anterior descending artery & 91 & 91 \\
\hline Left circumflex artery & 63 & 67 \\
\hline Left main coronary artery & 1 & 1 \\
\hline Length of hospital stay (d) & $2(1-4)$ & $8(6-10)$ \\
\hline
\end{tabular}

$P C l$, Percutaneous coronary intervention; $C A B G$, coronary artery bypass graft; $C A D$, coronary artery disease; $M I$, myocardial infarction. Data presented as percentage of the study population, or as median value (25th, 75th percentiles). *Stable angina was defined according to the system of the Canadian Cardiovascular Society; unstable angina was defined according to the Braunwald classification.

systematic overviews of these trials, 1 with information gathered in a standard pro forma from every principal investigator and 2 with data extracted from the published literature with intermediate and long-term follow-up outcomes, have also been reported. ${ }^{4-6}$ However, these studies were designed in the late 1980s and conducted and reported in the early 1990s. Since then, major technologic advances have been achieved in both PCI and CABG surgery and in the recognition of the importance of risk factor reduction. The results from trials that antedated the stent era are not reflective of the current practice of coronary revascularization because coronary stents are implanted in approximately $80 \%$ of all current PCIs and adjunctive pharmacologic ther- apies with glycoprotein IIb/IIIa inhibitors are frequently used. ${ }^{7}$

A systematic overview with individual patient data from recent clinical trials comparing PCI with multiple stenting against CABG surgery will provide the clinician caring for patients with multivessel CAD with meaningful treatment effect estimates regarding the advantages and drawbacks of each treatment strategy. The timing of this analysis is also advantageous, because it provides baseline data for comparisons with the results of drug-eluting stents in similar patients.

\section{Methods}

\section{Trial Selection and Data Management}

We intended to include all randomized clinical trials that compared PCI with multiple stenting versus CABG surgery in patients with multisystem CAD. To identify eligible trials we performed a MEDLINE search using the keywords "coronary stenting," "coronary artery bypass graft surgery," and "multisystem/multivessel disease." Furthermore, we examined the reference lists of identified articles, as well as the scientific sessions abstracts in Circulation, Journal of the American College of Cardiology, and European Heart Journal. Five trials were identified: Arterial Revascularization Therapies Study (ARTS), ${ }^{8}$ Stent or Surgery Trial (SoS), ${ }^{9}$ Argentine Randomized Trial of Percutaneous Transluminal Coronary Angioplasty Versus Coronary Artery Bypass Surgery in Multivessel Disease 2 (ERACI-2),${ }^{10}$ Medicine, Angioplasty, or Surgery Study 2 (MASS-2), ${ }^{11}$ and Angina With Extremely Serious Operative Mortality Evaluation (AWESOME). ${ }^{12}$

All of these trials included patients in whom coronary revascularization was indicated and appropriate by either strategy (PCI with multiple stenting or CABG surgery) by consensus agreement between the interventionalist and cardiac surgeon. There were, however, substantial differences in trial design (Table 1). ARTS and SoS were multinational studies, ERACI-2 was a multicenter study, and MASS-2 was a single-center study. The patient population of these trials also differed in terms of comorbidity, coronary anatomy, and periprocedural risk. In ARTS, high-risk patients were excluded, and approximately two thirds of the patients enrolled had 2-vessel disease. SoS had fewer restrictions on case selection, how the procedure was to be performed, and adjunctive therapy. In ERACI-2, the study population was composed predominantly by patients with unstable angina, and patients with left main stenosis judged to be good candidates for stenting were included $(\sim 5 \%)$. Finally, the MASS-2 trial included a slightly higher number of diabetic patients and patients with 3-vessel disease compared with the other 3 trials.

We excluded the medical treatment arm from MASS- 2 because this group was not in our prespecified comparison of PCI versus CABG. Finally, we also excluded the AWESOME trial, which compared long-term survival among patients assigned to either $\mathrm{CABG}$ or PCI with refractory myocardial ischemia and high risk of adverse outcomes. ${ }^{12}$ Patients with prior heart surgery, ongoing or very recent myocardial infarction (MI), and left ventricular ejection fraction less than $35 \%$ were included in AWESOME, and the characteristics of these patients are clearly different from the patient population of the 4 other trials included in this meta-analysis. 
TABLE 3. Clinical end points during follow-up

\begin{tabular}{|c|c|c|c|}
\hline & $\begin{array}{l}\text { PCI with stenting } \\
\text { (N = 1518) }\end{array}$ & $\begin{array}{c}\text { CABG } \\
(N=1533)\end{array}$ & $\begin{array}{c}\text { Adjusted hazard ratio } \\
(95 \% \mathrm{Cl})^{*}\end{array}$ \\
\hline \multicolumn{4}{|l|}{ Events at $30-\mathrm{d}$ follow-up } \\
\hline Death, MI, or stroke & $48(3.1 \%)$ & $74(4.8 \%)$ & $0.61(0.42-0.89)$ \\
\hline Death & $18(1.2 \%)$ & $16(1.0 \%)$ & $0.89(0.42-1.9)$ \\
\hline $\mathrm{MI}$ & $34(2.2 \%)$ & $51(3.3 \%)$ & $0.69(0.44-1.1)$ \\
\hline Stroke & $5(0.3 \%)$ & $11(0.7 \%)$ & $0.32(0.10-1.0)$ \\
\hline (re)CABG & $26(1.7 \%)$ & $5(0.3 \%)$ & $8.8(2.6-29)$ \\
\hline (re)PCI & $28(1.8 \%)$ & $3(0.2 \%)$ & $7.9(2.4-26)$ \\
\hline Death or MI & $45(3.0 \%)$ & $66(4.3 \%)$ & $0.65(0.44-0.97)$ \\
\hline (re)CABG or (re)PCI & $51(3.3 \%)$ & $8(0.5 \%)$ & $7.8(3.3-18)$ \\
\hline Death, MI, stroke, (re)CABG, or (re)PCI & $84(5.5 \%)$ & $81(5.3 \%)$ & $1.0(0.73-1.4)$ \\
\hline \multicolumn{4}{|l|}{ Events at 1-y follow-up } \\
\hline Death, MI, or stroke & $132(8.7 \%)$ & $140(9.1 \%)$ & $0.95(0.74-1.2)$ \\
\hline Death & $46(3.0 \%)$ & $43(2.8 \%)$ & $1.0(0.64-1.6)$ \\
\hline $\mathrm{MI}$ & $88(5.8 \%)$ & $85(5.5 \%)$ & $1.1(0.78-1.5)$ \\
\hline Stroke & $17(1.1 \%)$ & $23(1.5 \%)$ & $0.74(0.37-1.5)$ \\
\hline (re)CABG & $94(6.2 \%)$ & $21(1.4 \%)$ & $4.6(2.8-7.6)$ \\
\hline (re)PCl & $196(13 \%)$ & $48(3.0 \%)$ & $4.4(3.2-6.2)$ \\
\hline Death or MI & $118(7.8 \%)$ & $121(7.9 \%)$ & $0.98(0.75-1.3)$ \\
\hline (re)CABG or (re)PCI & $272(18 \%)$ & $68(4.4 \%)$ & $4.4(3.3-5.9)$ \\
\hline Death, MI, stroke, (re)CABG, or (re)PCI & $363(24 \%)$ & $201(13 \%)$ & $1.9(1.6-2.3)$ \\
\hline
\end{tabular}

$\mathrm{PCl}$, Percutaneous coronary intervention; $C A B G$, coronary artery bypass graft; $C l$, confidence interval; $M I$, myocardial infarction. *Adjusted for age, gender, previous $\mathrm{MI}$, diabetes mellitus, peripheral vascular disease, hypertension, enrollment diagnosis, number of diseased vessels, ejection fraction, smoking status, aspirin use, $\beta$-blocker use, calcium channel blocker use, long-acting nitrates use, and statin use.

Principal investigators of each study group were contacted, and individual patient data were requested regarding a broad range of baseline characteristics, medication use, procedural results, and clinical outcome. Outcome events of interest included death, MI, stroke, repeat revascularization (PCI or CABG), and anginal status at 1-year follow-up. Data were transferred in electronic format to the coordinating center at the Clinical Epidemiology Unit, Thoraxcenter, Rotterdam, The Netherlands. Rigorous checks for data completeness, consistency, and agreement with the main published reports were performed, and finally an electronic database was composed consisting of individual patient data of all 4 trials.

\section{Definitions of Variables and Clinical End Points}

As expected, we found differences in clinical end point definitions in ARTS, SoS, ERACI-2, and MASS-2, especially in the definition of MI. However, we did not attempt to reclassify outcome events retrospectively, because this not only would be impractical but, more important, it also would create the potential for bias. Because the outcome definitions were the same within a particular trial and the statistical method was based on a comparison of treatment groups within each trial, no biases would be expected to result from our approach. ${ }^{13}$

The primary clinical outcome of this meta-analysis was the composite of death, MI, or stroke at 1 year follow-up. Secondary end points included death; the composite of death or MI; repeat revascularization (PCI or CABG); and the composite of death, MI, stroke, and repeat revascularization.

\section{Statistical Analysis}

Variables are presented as median (25th, 75th percentiles) values, counts, and percentages. Differences in baseline variables between patients allocated to PCI and multiple stenting or CABG were evaluated with Fisher's exact tests or Kruskal-Wallis tests as appropriate. Kaplan-Meier event curves were constructed, and differences between the 2 groups of patients were compared by log-rank tests. Simple Cox proportional hazard regression models were applied to further evaluate the relation between allocated treatment and the incidence of primary and secondary end points. The reported hazard ratios (HRs) and 95\% confidence interval (CI) are adjusted for between-trial outcome differences, as well as for age, CAD risk factors, cardiovascular history, comorbidities, and medication. To check for statistical evidence of heterogeneity, we studied to what extent the $-2 \log$ likelihood of the regression models was improved by adding trial-allocated treatment interaction terms ( $\chi^{2}$ tests were applied). Furthermore, the consistency of treatment effects were evaluated in prespecified subgroups according to age, gender, diabetes mellitus, smoking habits, and extent of coronary disease. All analyses were performed according to the intention-to-treat principle.

\section{Results}

\section{Patients and Initial Procedures}

Between June 1995 and June 2000, 3051 patients at 113 participating centers were randomly allocated to undergo PCI with multiple stenting $(\mathrm{N}=1518)$ or CABG surgery 

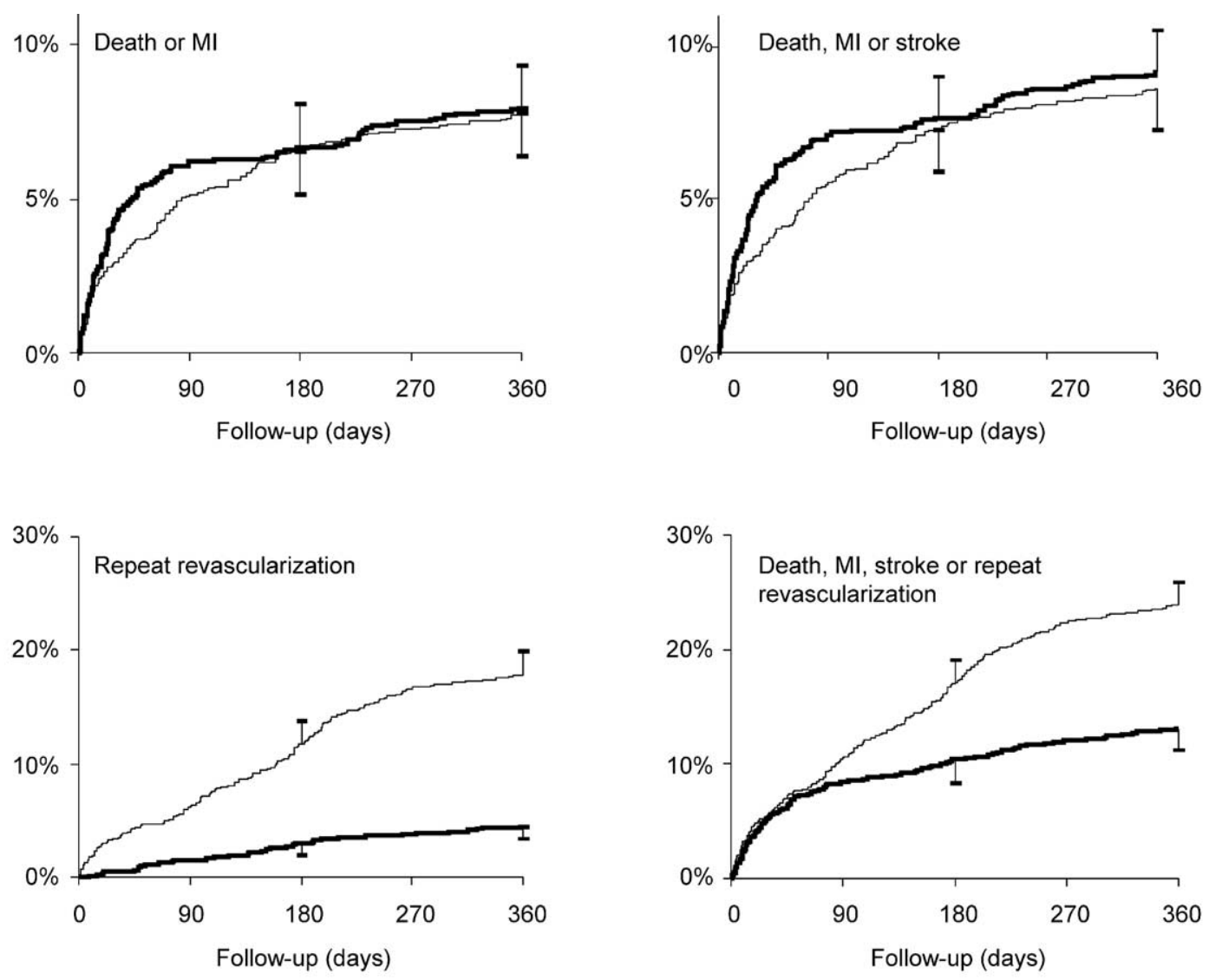

Figure 1. Incidence of adverse cardiovascular events and repeat revascularization procedures during 1-year follow-up in patients allocated to PCI with multiple stenting or CABG surgery (bold line).

$(\mathrm{N}=1533)$. Baseline characteristics are presented in Table 2. The median interval between randomization and treatment was 10 (5-23) days for patients allocated to PCI with multiple stenting and 23 (14-42) days for patients allocated to CABG surgery. Eighty-nine percent of patients allocated to PCI with multiple stenting and $96 \%$ of those allocated to CABG surgery received the assigned treatment.

Among the patients in the group with PCI and multiple stenting, a median of 2 (2-3) lesions with significant stenosis were successfully revascularized. Stents were implanted in $79 \%$ of lesions; the median number of stents implanted per patient was 2 (2-3). Glycoprotein IIb/IIIa inhibitors were applied at the index procedure in $6.7 \%$ of patients. Among patients allocated to CABG surgery, a median of 3 (2-3) anastomoses were performed with the use of 2 (2-3) conduits. In $90 \%$ of the patients at least 1 arterial conduit was used. Complete revascularization was achieved in $54 \%$ of patients allocated to PCI with multiple stenting compared with $82 \%$ of patients allocated to CABG surgery $(P<.001)$.

\section{Clinical Outcomes}

Patients randomized to PCI with multiple stenting had a significantly lower incidence of death, MI, or stroke at 30-day follow-up than those randomized to CABG surgery (3.1\% vs $4.8 \%$ events; HR 0.61 and $95 \%$ CI $0.42-0.89 ; P=$ $.01)$. As shown in Table 3 , this event reduction was mainly because of a lower incidence of nonfatal events. In contrast, PCI with multiple stenting was associated with an increased need for repeat revascularization procedures at 30 days (3.3\% vs $0.5 \%$ repeat procedures; HR 7.8 and $95 \% \mathrm{CI}$ 3.3-18.3; $P<.001)$.

The cumulative incidence of death, MI, or stroke at 1-year follow-up was similar in both groups: $8.7 \%$ after PCI with multiple stenting and $9.1 \%$ after CABG surgery (HR 0.95 and $95 \%$ CI $0.74-1.2 ; P=.63$; Figure 1 , Table 3 ). There was also no difference in 1-year mortality or in the composite of death or MI. Repeat revascularization occurred more frequently in patients allocated to PCI with multiple stenting than in those allocated to CABG surgery $(18.0 \%$ vs $4.4 \% ; P<.001)$. Consequently, the incidence of 
any major adverse cardiac event after 1-year follow-up was higher after PCI with multiple stenting than after CABG surgery (24.0\% vs $13.0 \%$; HR 1.9 and $95 \%$ CI 1.6-2.3). The percentage of patients who were in Canadian Cardiovascular Society functional class 0 (ie, free from angina) at 1 year was lower after PCI with multiple stenting than after CABG surgery (77\% vs $82 \% ; P=.002$; Figure 2 ). The percentage of patients in Canadian Cardiovascular Society class 0 or I was similar in both groups (90\% vs $89 \% ; P=.2)$.

\section{Heterogeneity}

In unadjusted and adjusted analyses, we found global quantitative evidence of heterogeneity between the 4 trials for the primary end point of death, MI, or stroke $(P<.001)$. We also found heterogeneity when ERACI-2 $(P=.01)$, MASS-2 $(P=.01)$, or SoS $(P=.001)$ were removed individually from the model. There was no heterogeneity when ERACI-2 and MASS-2 were both excluded $(P=.1)$. The heterogeneity was limited to the first 30 days and no longer present from 30 days to 1 year $(P=.2)$. The estimated treatment effect at 1-year follow-up based only on the ARTS and SoS trials was similar to the estimated treatment effect based on all 4 trials together. This is true for the primary end point (HR 0.97 and $95 \%$ CI $0.71-1.3$ vs HR 0.85 and $95 \% \mathrm{CI} 0.74-1.2)$ and secondary end points including mortality (HR 1.3 and 95\% CI $0.66-2.6$ vs HR 1.0 and 95\% CI 0.64-1.6) and repeat revascularization (HR 5.5 and $95 \%$ CI 3.8-7.8 vs HR 4.4 and 95\% CI 3.3-5.9).

\section{Subgroup Analyses}

We found no evidence of a differential treatment effect between the 2 revascularization strategies with regard to the 1 -year incidence of the primary composite end point across various prognostically important subpopulations, including those grouped by age, gender, diabetes mellitus, smoking, and number of diseased vessels (Figure 3). In the subpopulation of 549 patients with diabetes mellitus, 1-year mortality occurred in $5.6 \%$ of patients allocated to PCI with multiple stenting and in $3.5 \%$ of those allocated to CABG surgery (HR 1.6 and 95\% CI 0.72-3.6; $P=.3$ ).

\section{Discussion}

In patients with multisystem coronary disease, PCI with liberal use of stents was associated with a similar incidence of death, MI, or stroke at 1-year follow-up as in CABG surgery. This observation is in accordance with previous reports. ${ }^{3}$ Despite the use of stents, however, the need for repeat revascularization was considerably higher after PCI, although the observed gap with CABG surgery has narrowed from approximately $30 \%$ reported in the pre-stent era to approximately $14 \%$ in the present report. ${ }^{4}$ Bypass surgery was still associated with a slightly lower frequency of

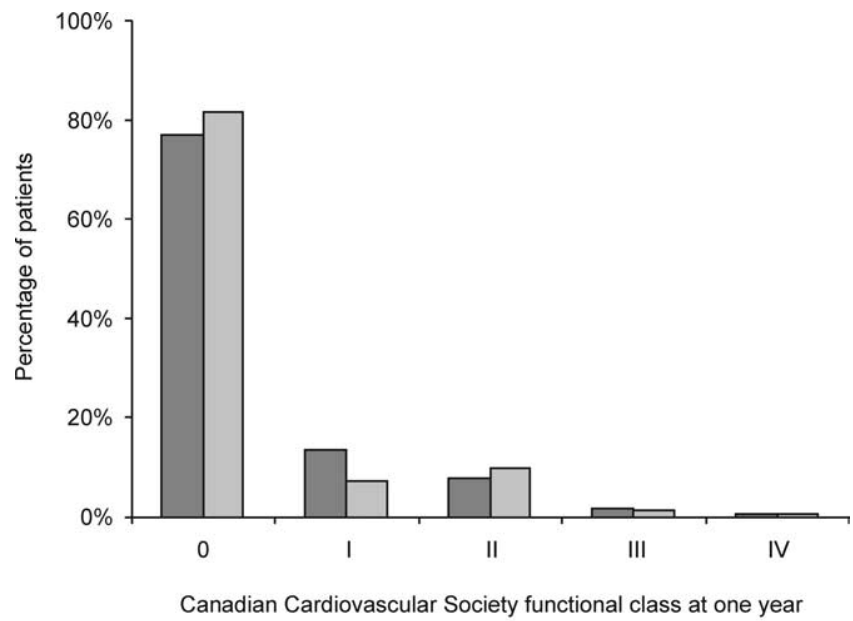

Figure 2. Anginal status at 1-year follow-up in patients allocated to $\mathrm{PCI}$ with multiple stenting (dark) or CABG surgery (light).

recurrent angina, but the difference with angioplasty has decreased also in this respect. ${ }^{4}$

One might argue that our findings are not particularly surprising because they could have been retrieved from the individual trial reports. Indeed, in the larger ARTS and SoS trials, PCI with multiple stenting and CABG surgery had similar event rates for the primary end point, whereas in ERACI-2, PCI was associated with better outcome, and in MASS-2, CABG surgery was associated with better outcome. However, substantial differences between metaanalyses of the published literature and meta-analyses of individual patient data have been reported. ${ }^{14,15}$ The most important reason for these variations is that meta-analyses of individual patient data are based on a time-to-event analysis, whereas meta-analyses of the literature are simply based on end points at a specific point in time. ${ }^{16}$ The direction and magnitude of these variations cannot be predicted in advance. In general, results obtained from metaanalyses of individual patient data offer least biased and more reliable treatment effect estimates, and whenever possible should be preferred over meta-analyses of the literature.

The question as to what extent the observed results can be extrapolated to routine clinical practice is challenging. We appreciate that high-risk patients with left main CAD, severe left ventricular dysfunction, and diffuse disease were not allowed to participate in the trials that were included in this meta-analysis. As a result, the median left ventricular ejection fraction in our study population was $60 \%$, which is certainly not a representative figure of candidates for revascularization who present to an average clinic. ${ }^{17}$ It is also important to note that an unspecified number of patients with anatomy technically unsuitable for PCI were appropri- 


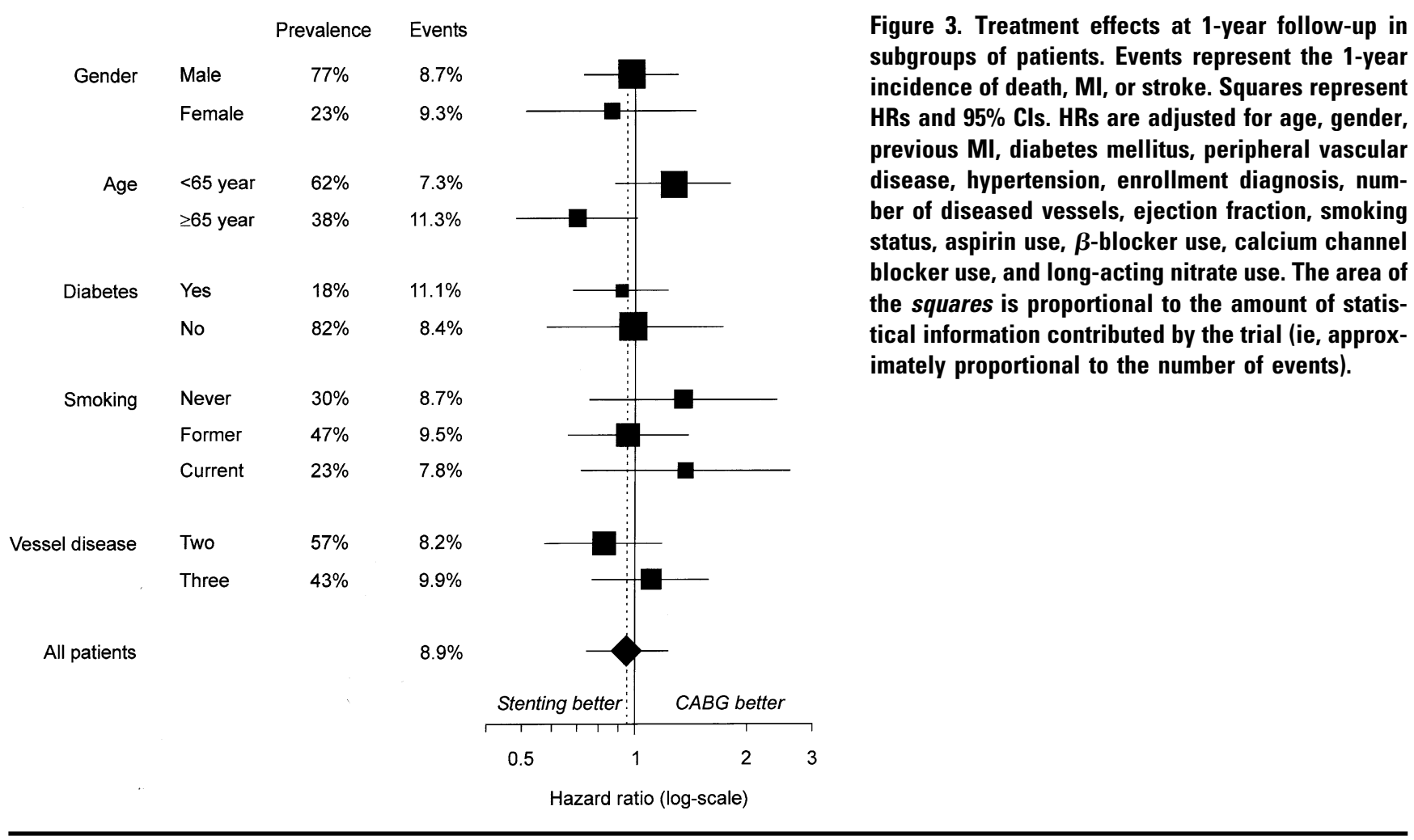

ately excluded. Therefore, in routine clinical practice a higher incidence of adverse cardiac complications and repeat revascularizations should be expected than was observed in our data. Still, although absolute treatment effects may be different in clinical practice, we do not anticipate a differential relative treatment effect, because in our data relative treatment effects were similar in a broad range of prognostically important patient subgroups.

The Bypass Angioplasty Revascularization Investigation trial demonstrated a significantly higher mortality incidence at 5 (35\% vs $19 \%$ ) and 7 years (44\% vs 24\%) among diabetic patients with multivessel disease who were treated with balloon angioplasty compared with surgery. ${ }^{18,19}$ Our data suggest that mortality may also be higher in diabetic patients with multivessel disease who undergo PCI with multiple stenting. The limited number of patients and the short duration of follow-up may have masked any significant differences. Moreover, the periprocedural use of glycoprotein IIb/IIIa inhibitors in the PCI group may have conceivably played a role in decreasing the mortality associated with PCI in our patient population. ${ }^{20}$ With the prevalence of CAD and diabetes increasing at staggering rates, ongoing studies will provide further insights on the optimal management of multivessel disease in diabetic patients.

The widespread use of coronary stenting has significantly decreased the need for emergency CABG surgery among patients treated with PCI. The recent introduction of drug-eluting stents has decreased the incidence of coronary restenosis and the need for repeat revascularization. ${ }^{21}$ Whether future stent technology will decrease the rates of repeat revascularization in patients with multivessel disease to rates equivalent to those after CABG surgery is a possibility that will need to be assessed in future studies. Recently published data from the RESEARCH registry have shown a significant $65 \%$ reduction in 1-year repeat revascularization in consecutive patients with multivessel disease treated with sirolimuseluting stents compared with bare metal stents $(3.7 \%$ vs $10.9 \%$ repeat procedures).$^{22}$ In this scenario, a strategy to modify the natural course of the atherosclerotic disease itself (ie, nonrestenosis-related complications) becomes the main focus of attention after percutaneous or surgical treatment of multivessel disease. Similarly, evidence is emerging that statins could decrease perioperative mortality and reduce the risk of coronary atherosclerotic events in patients undergoing PCI. ${ }^{23}$

The main limitation of this meta-analysis is the relatively short follow-up period limited to 1 year. Long-term (5-year) follow-up of this cohort of patients is planned. It is also likely that patients included may represent a selected population of low-to-moderate risk patients with multisystem disease, thus limiting the generalizability of the results to more complex subsets of patients. It is important to note that 
this meta-analysis of randomized trials does not compare procedures but clinical outcomes of an initial revascularization strategy for patients who are eligible and amenable to be treated with each therapy (PCI or CABG). Moreover, because patients undergoing PCI or CABG are subsequently managed medically, late survival could not necessarily be reflective of the initial revascularization method. Finally, we realize that the differences in clinical end point definitions between the trials that were included in this meta-analysis, especially the differences in MI definitions, may complicate the extrapolation of the presented data to individual patients.

\section{Conclusions}

One year after the initial procedure, PCI with multiple stenting and CABG surgery provided a similar degree of protection against death, MI, or stroke for patients with multisystem CAD. Repeat revascularization procedures remain higher in PCI with multiple stenting compared with CABG surgery, but the difference has narrowed in the era of stenting relative to the pre-stent era.

We gratefully acknowledge the support of all trial investigators in the individual studies and the particular help of Fiona Nugara (Clinical Trials and Evaluation Unit, Royal Brompton Hospital, London) in providing data. We also acknowledge the support of the following companies in the original trials: Cordis/Johnson and Johnson (ARTS), Guidant, Medtronic, and Boston Scientific (SoS).

\section{References}

1. Gaziano JM. Global burden of cardiovascular disease. In: Braunwald E, Zipes D, Libby P, editors. Heart disease. A textbook of cardiovascular medicine. 6th ed. Philadelphia: WB Saunders Company; 2001. p. 1-26.

2. Rigter $\mathrm{H}$, Meijler AP, McDonnell J, et al. Indications for coronary revascularisation: a Dutch perspective. Heart. 1997;77:211-8.

3. Rihal CS, Raco D, Gersh BJ, et al. Chapter 27. Impact of revascularization procedures in chronic coronary artery disease on clinical outcomes: a critical review of the evidence. In: Yusuf S, Cairns JA, Camm AJ, Fallen EL, Gersh BJ, editors. Evidence-based cardiology. Second edition. London, UK: BMJ Books; 2003. pp. 339-59.

4. Pocock SJ, Henderson RA, Rickards AF, et al. Meta-analysis of randomised trials comparing coronary angioplasty with bypass surgery. Lancet. 1995;346:1184-9.

5. Sim I, Gupta M, McDonald K, et al. A meta-analysis of randomized trials comparing coronary artery bypass grafting with percutaneous transluminal coronary angioplasty in multivessel coronary artery disease. Am J Cardiol. 1995;76:1025-9.

6. Hoffman SN, TenBrook JA, Wolf MP, et al. A meta-analysis of randomized controlled trials comparing coronary artery bypass graft with percutaneous transluminal coronary angioplasty: one to eightyear outcomes. J Am Coll Cardiol. 2003;41:1293-304.
7. Eeckhout E, Wijns W, Meier B, et al. Indications for intracoronary stent placement: the European view. Working Group on Coronary Circulation of the European Society of Cardiology. Eur Heart J. 1999;20:1014-9.

8. Serruys PW, Unger F, Sousa JE, et al. Comparison of coronary-artery bypass surgery and stenting for the treatment of multivessel disease. N Engl J Med. 2001;344:1117-24.

9. SoS Investigators. Coronary artery bypass surgery versus percutaneous coronary intervention with stent implantation in patients with multivessel coronary artery disease (the Stent or Surgery trial): a randomised controlled trial. Lancet. 2002;360:965-70.

10. Rodriguez A, Bernardi V, Navia J, et al. Argentine Randomized Study: Coronary Angioplasty with Stenting versus Coronary Bypass Surgery in patients with Multiple-Vessel Disease (ERACI II): 30-day and one-year follow-up results. ERACI II Investigators. J Am Coll Cardiol. 2001;37:51-8.

11. Hueb W, Soares PR, Gersh BJ, et al. The Medicine, Angioplasty, or Surgery Study (MASS-II): a randomized, controlled clinical trial of three therapeutic strategies for multivessel coronary artery disease. J Am Coll Cardiol. 2004;43:1743-51.

12. Morrison DA, Sethi G, Sacks J, et al. Percutaneous coronary intervention versus coronary artery bypass graft surgery for patients with medically refractory myocardial ischemia and risk factors for adverse outcomes with bypass: a multicenter, randomized trial. J Am Coll Cardiol. 2001;38:143-9.

13. Direct Thrombin Inhibitor Trialists' Collaborative Group. Direct thrombin inhibitors in acute coronary syndromes: principal results of a metaanalysis based on individual patients' data. Lancet. 2002;359:294-302.

14. Stewart LA, Parmar MK. Meta-analysis of the literature or of individual patient data: is there a difference? Lancet. 1993;341:418-22.

15. Stewart LA, Clarke MJ. Practical methodology of meta-analyses (overviews) using updated individual patient data. Cochrane Working Group. Stat Med. 1995;14:2057-79.

16. Duchateau L, Pignon JP, Bijnens L, et al. Individual patient- versus literature-based meta-analysis of survival data. Time to event and event rate at a particular time can make a difference, an example based on head and neck cancer. Control Clin Trials. 2001;22:538-47.

17. Brener SJ, Lytle BW, Casserly IP, et al. Propensity analysis of longterm survival after surgical or percutaneous revascularization in patients with multivessel coronary artery disease and high-risk features. Circulation. 2004;109:2290-5.

18. Influence of diabetes on 5-year mortality and morbidity in a randomized trial comparing CABG and PTCA in patients with multivessel disease: the Bypass Angioplasty Revascularization Investigation (BARI). Circulation. 1997;96:1761-9.

19. Seven-year outcome in the Bypass Angioplasty Revascularization Investigation (BARI) by treatment and diabetic status. J Am Coll Cardiol. 2000;35:1122-9.

20. Marso SP, Lincoff AM, Ellis SG, et al. Optimizing the percutaneous interventional outcomes for patients with diabetes mellitus: results of the EPISTENT (Evaluation of platelet IIb/IIIa inhibitor for stenting trial) diabetic substudy. Circulation. 1999;100:2477-84.

21. Morice MC, Serruys PW, Sousa JE, et al. A randomized comparison of a sirolimus-eluting stent with a standard stent for coronary revascularization. N Engl J Med. 2002;346:1773-80.

22. Lemos PA, Serruys PW, van Domburg RT, et al. Unrestricted utilization of sirolimus-eluting stents compared with conventional bare stent implantation in the "real world": the Rapamycin-Eluting Stent Evaluated At Rotterdam Cardiology Hospital (RESEARCH) registry. Circulation. 2004;109:190-5.

23. Serruys PW, de Feyter P, Macaya C, et al. Fluvastatin for prevention of cardiac events following successful first percutaneous coronary intervention: a randomized controlled trial. JAMA. 2002;287: 3215-22. 